\title{
Wage Distribution Disparities in the Labor Market
}

\author{
Nasfi Fkili Wahiba \\ Doctor of Economics, Research Unit "Enterprise Economy Environment" \\ Higher Institute of Management, University of Gabes, Tunisia. \\ E-mail: Nasfiwahiba@yahoo.fr
}

DOI: 10.6007/IJAREMS/v3-i1/599 URL: http://dx.doi.org/10.6007/IJAREMS/v3-i1/599

\begin{abstract}
Many developing countries have undertaken in the eighties a series of reforms of policies, the primary objective of the reforms was the revival of economic activities in these countries challenged by severe economic and financial crises. In this context, trade policy had been placed at the center of development policies advanced under the "Washington Consensus."

Nevertheless, the mixed consequences of the implementation of the Washington Consensus have generated criticism increasingly severe. It was alleged that this consensus have focused on competition and efficiency rather than equity and solidarity, which resulted incredible rise in inequality.

We propose to focus on inequality in the labor market; we study the differences between workers by calculating inequality and conducting an econometric study to detect the size of the effect of opening to the global economy on inequality.
\end{abstract}

Keywords: Wage, Labor Market, Inequality, Washington Consensus, Openness.

JEL Classification: D31, F13, F16.

\section{Introduction}

The debt crisis in the early 80 s resulted the majority of developing countries to undertake a process of reform to promote growth and to overcome the debt crisis. It was to restore economies more open to the world with the adoption of policies inspired an agreement called "Washington consensus" which aimed to guide the overall global economic policies towards the objectives of fiscal austerity and liberalization of trade and capital.

However, several criticisms have been directed against the consensus suggesting that it could not achieve its intended objectives, thus, countries with strictly followed the recommendations of the Washington Consensus could not achieve better economic results, This consensus has led to an incredible rise in inequality and worsening poverty in the world.

Thus, the opening to the global economy has resulted in rapid changes in different sectors as well as in the application of skills and know-how in favor of most skilled in the labor market, new jobs created require, in fact, the implementation of advanced technologies and adapted trained workers with high levels of qualifications.

In this context, we will examine the responsibility of the openness to the global economy in terms of increased inequality in the Tunisian labor market and especially within the 
private sector. We present the foundations of the Washington Consensus and overruns of consensus by analyzing different perspectives.

\section{Washington Consensus and increased inequality}

Based on the policies of the liberal economic orthodoxy, the "Washington Consensus" has tried to orient all economies to the liberalization of trade and capital. The reforms adopted by developing countries have formed a new axis of a strategy, with financial support from the World Bank and the International Monetary Fund, would help indebted countries to ensure access to international markets. However, consensus could not achieve the expected results given the worsening of social problems in the country.

\section{Basics of the Washington Consensus}

The Washington Consensus has a set of reforms that Latin American countries undergoing economic dirigisme, could adopt to encourage the return of private capital in the region after the crippling debt crises of the eighties. Indeed, (Williamson 1990) defined a reform program, formulated especially towards Latin America; its recommendations quickly became a model for the entire developing world, they are based on macroeconomic and especially fiscal discipline, a market economy and openness to the world and to foreign direct investment.

Indeed, the Washington Consensus is defined through two categories of commandments, the first concerns the stabilization measures intended to control inflation and improve the balance of payments in order to keep debt at an acceptable level. While the second was about to open the economy to foreign trade by lowering trade barriers, changing sectoral composition of production and encouraging the private sector, these measures were described as structural. Similarly, Williamson argued that interest rates should be determined by the market and the real rates must be positive and moderate to development financing.

Following a neoclassical perspective, stating that the search for a balanced budget and the disengagement of the State is made by reducing of public spending rather than increasing tax burden, Williamson emphasizes the reduction of subsidies. The aim is to reorient public expenditure towards projects related to education, health and infrastructure investments.

Also the Washington Consensus has focused on structural measures such as trade liberalization with a view to promoting exports in order to reduce or eliminate tariff and non tariff barriers. In fact, the return to the theory of comparative advantage condemns import substitution strategies that give way to policies promoting exports representing an international integration based on factor endowments.

The Washington Consensus has even questioned the state intervention in proclaiming the superiority of the market, with a reduction of barriers to entry and exit markets to promote free competition. Williamson has made other recommendations in relation to the competitiveness, tax reforms and property rights.

Therefore, the precepts advanced by Williamson are the foundation of the first generation of reforms of structural adjustment programs carried out under the aegis of the International Monetary Fund and the World Bank who then decided to make loans to countries adopting policies based on these theories. 
Indeed, the policies of International Financial Institutions from the eighties reflect a radical shift in thinking to the problems of developing countries. Therefore, the measures considered were based on two fundamental axioms namely the superiority of laissez-faire to interventionism and free trade to protectionism while leading to an essential conclusion that free trade is beneficial to all countries, whether industrialized or not.

International Financial Institutions support the idea that the implementation of liberal economic policies of the Washington Consensus is necessarily in the sense of improving the economic and social situation of developing countries, while there are many who advance several criticisms of this consensus by stating that it requires a few more steps to be perform.

\section{Exceeding of Washington Consensus}

For liberals problems encountered in developing countries are the consequences of a bad choice of strategy, for them, these countries have diverged from the path that allows them to catch up and only the recommendations of the Washington Consensus can put the countries on the right track. However, many economists have found that these recommendations have not produced the expected results.

Thus, countries with scrupulously followed the Washington Consensus could not achieve better economic results, in fact, the various consequences of the application of Washington Consensus have generated increasingly severe criticism. Moreover, (Milanovic 2003) noted that during the last two decades, which have seen an acceleration of globalization, growth has slowed and inequalities between countries, which was slightly reduced in the years 1960-1970, were very increased after.

Similarly, (Rodrik 1998) verified that trade liberalization was unable to promote growth and development, argument also advanced by (Stiglitz 1998) suggesting that is not possible to establish the existence of a positive and significant impact of the Washington consensus because its objectives are not achieved globally. It also appears that the failure of consensus is due to a very high confidence in the functioning of the market, as a paradigm of the economy.

Faced with these criticisms, Williamson said that some of his remarks were distorted. For him, The Latin American commitments should not be identical to those of European countries. Moreover, Rodrik.D noted in 2004 and 2006 that countries have applied accurately the guidelines of the Washington Consensus have not made the progress expected, given that the growth gap between these countries and those of other regions continues to grow. Also, the performance of these countries is not as good as before the implementation of the recommendations of the Washington Consensus. While states which have moved away from these recommendations and have implemented other types of policies based on national realities were able to record the best economic performance.

In this regard Rodrik.D notes that South Korea and Taiwan were not involved in the way of deregulation and liberalization, but instead privatize its countries have maintained a fairly strong public sector and have not hesitated to maintain their trade barriers. They opted for very different measures of those recommended by the International Financial Institutions and they had, however, remarkable results in economic growth. On the other hand, the consensus has been criticized for having focused on competition and efficiency rather than equity and solidarity. (Williamson 2004) himself noted that no consensus has emerged at that time the necessity taking into account of equity. 
It follows that the Washington Consensus has resulted in an increase in inequality and worsening poverty in the world. The continuous increase in inequality is realized on two levels, on the inside, the enlargement of the range of wages and salaries in the enterprise reflects the trend of increasing social inequality. While in the international level, rising inequality is between rich and poor countries disadvantaged by the terms of an unequal exchange and also by the size of the debt.

It is in its differences in wealth that inequality found its internal dynamics. Thus, public institutions must strike a balance between costs and benefits, The International Monetary Fund and the World Bank have considered these issues by integrating them into their programs.

Similarly, (Treval 2003) suggests that consensus could not achieve all its objectives, since it did not help to solve the structural and institutional problems that hamper growth. For Treval the Washington Consensus does not cover three aspects of African development necessary for sustainable growth: sustainable economy, social capital and the role of the state.

Regarding the first aspect, it focuses on the imbalance that exists in most African countries, between urban sector and the rural informal sector which suffers from unemployment and poverty quite high compared to the urban sector; this suggests that rural areas are dependent on fiscal transfers and workers to urban areas. The second aspect is to avoid the privilege of developing structured sector than the informal sector and to ensure that regulation is well suited for both sectors.

In addition, a need to state intervention was required and discovered, because the majority of African countries need development and not reduction of the public sector, which requires the institutional capacity especially in the fields of regulation, service delivery and social spending. Moreover, even the World Bank eventually shows in his annual report dated in 1997 the main functions of the state such as investment in basic services and infrastructure and environmental protection as well as the equity. (World Bank 1997; Hugon 1999).

In this context, (Stiglitz 1998) and (Rodrik 2004) sought to form the path of postconsensus. Thus, the conclusions of "first generation" reforms should be accompanied by an application of essential reforms relating to the "second generation" forming a series of measures improving public institutions such as legal systems, financial systems and sectors policies. Similarly, the new Washington consensus favors more the issue of the skewed distribution of income, indeed in proportion as developing countries begin to recover their economic crisis, the benefits should go to the poor.

As a result, measures of post consensus aimed at helping the poor. They insist on a better quality of education, and they strongly recommend programs giving property title and greater access to microcredit to improve opportunities for income generation for the poor. Thus, and in order to complete the reforms of the first generation, (Rodrik 2004) highlights the need to take into account other additional recommendations: Good governance, respect for the rules of the World Trade Organization, a cautious opening of the capital account and continuation of the fight against inflation and poverty.

Indeed, it is hardly possible to oblige States to apply uniformly policies and strategies as they are considered good practice, but rather it should be left a political space for developing countries to entrust them with the flexibility to define the strategies that best meet the particular circumstances of each state. 
Rodrik. D also asserts that the best development strategy involves three essential components. He first, emphasized the importance of a diagnosis which must be done by governments to be able to specify constraints to economic growth, while choosing priority sectors to intervene. Second, the economist noted the need to develop guidelines and policies to alleviate the constraints already identified. Finally, Rodrik. D suggested that the diagnosis and the development constraints should be institutionalized. Thus, in order to conduct good development strategies, it was necessary to adapt and develop new arrangements following the evolution of the economic and financial situation, it follows that development policies must be set while respecting the realities and needs of each country.

On the same basis, and to assert the need for several additional recommendations (Stiglitz 1998) argues that, despite some benefits of programs "liberalization-stabilization privatization" of the Washington Consensus, it is perfectly remarkable that these programs manifested by huge glaring errors and failures. Indeed, Stiglitz blames rich countries to have encouraged the opening regardless of the social cost, for him, the liberal policy that had the most negative consequences for the development is the liberalization of capital movements. Thus, by adopting the recommendations of the Washington Consensus, these countries have promoted a particular model of globalization beneficial for some but bad for others who are facing a problem of worsening poverty and inequality.

On the other hand, the International Monetary Fund (IMF) has been the subject of much criticism from Stiglitz, for its interventions in developing countries and recommended policies. Stiglitz accuses the Fund to have favored bankruptcy and recession throughout the world, he attacked with virulence against the management of the crisis by the IMF stating that it is this injurious management which further deepened and broadened the crisis.

Indeed, with the outbreak of the crisis, Fund officials have decided to stop devaluation and restore the confidence of financial markets, To do this, they insisted on an increase in interest rates for the various governments in order to compress domestic demand, overturn the deficit in the trade balance and the return of foreign exchange to stop the fall of the local currency.

According to Stiglitz, the approach taken by the IMF was deeply flawed, as rising interest rates have led to the bankruptcy of companies and banks that were already indebted, This has exacerbated the financial crisis. Similarly, the compression of domestic demand has not been beneficial, since it has led to falling production.

In brief the Washington consensus could not achieve the desired objectives and growth has been hampered in many developing countries with problems not included in the reforms of the consensus. Similarly it has never discussed the social effects that may be harmful for all developing countries with regard to the considerable increase in inequality after opening.

\section{Inequality in the labor market}

The last decade has been marked by several mutations affecting the labor market by guiding enterprises to new strategies in production and work organization, these changes are due to contemporary economic developments and confrontation against the foreign competition after the opening.

Indeed, current strategies adopted to new market conditions are under research competitiveness and profitability, which was originally the occurrence of a phenomenon of 
segmentation of the labor market. Accordingly, changes in market structures based on labor flexibility caused discrimination and exclusion of certain groups of workers thus creating inequalities. On this basis, it is important to focus on the segmentation that defines the labor market after globalization.

\section{The segmentation of the labor market in developing countries}

Analysis of the effects of the opening may be based on two fundamental results from the discussions held in recent years. First, the recognition that there are winners and losers, especially those who were unable to take advantage of new opportunities offered by the integration and those who have done so, Then, the interaction of globalization with other contemporary economic and social changes. These results contradict those who make globalization a solution to the problems of the world and those who charge him of all evils.

Internally in developing countries, the income gap between the richest and poorest continues to widen as a result of participation of countries in international trade which is responsible for the segmentation of the labor market, particularly for the most competent, hence the increasing disparities between employees remuneration. Less skilled are the first victims of the development of international trade as they recorded a reduction of their wages or worse, lose their job, which reinforces existing inequalities.

The phenomenon of segmentation of the labor market comes from the objective of achieving higher levels of productivity, especially that of employees. From the outset, entrepreneurs looking to gain a staff with more skill, more experience and better performance. Based on the foregoing, the segmentation of the labor market may affect job and wage inequality by reinforcing existing disparities in several forms, it is in fact, and disparities between certain classes or groups (men and women, skilled-unskilled), these inequalities can hinder the development process and cause the exclusion of some individuals in the labor market.

Therefore, the forms of segmentation of the labor market are causing social and occupational stratification designed as a classification that relates to the main differentiation process at the professional level which relate to various aspects of social status. Similarly, an unequal distribution of wages between sectors or even within these is often associated with stratification, it follows that stratification and inequality are bonded to each other in spite of their difference. The first focuses on the measurement of the difference in Welfare between groups of individuals, while the stratification distinguishes between group members and others belonging to several groups based on a distribution of households by income.

In this context, the stratification is based on the heterogeneity of individual skills from following the acquisition of human capital or equipment facilitating membership in professional statutes that guarantee a certain level of remuneration. That being said, it must be noted that this stratification reinforces the persistence of inequality across generations. The occupation is in this context an important factor of social differentiation, because the best incomes often characterize activities that require higher levels of study and training.

Indeed, the new jobs created after the opening to the global economy, require the implementation of advanced technologies, which requires hiring well-trained and having high levels of education. Thus, on the basis of the theory of segmented labor market, differences between jobs in a sector as well as in profitability workers have an influence on the distribution of wages and employment, indeed, the heterogeneity of activities in sectors and differences in 
talents, skills and working conditions affect the dispersion of wages. Therefore, the wages paid to jobs based solely on physical exertion differ from those requiring more knowledge, reflection, synthesis, versatility and creativity, hence the classification of workers according to their qualifications.

Thus, the increasing global demand for ideas and innovation allows both the growth in the number of more competent and increase their earnings. Conversely, the demand for less qualified decreased, they are in fact excluded from the productive system as they do not master new technologies, so this is the thesis of technical progress biased towards more skilled which explains the increase in inequality.

The major challenge for developing countries is to arbitrate between the advantages and disadvantages of globalization, in the sense that competition forces an economy to improve its production is usually manifested by problems of unequal distribution of benefits where individuals benefit from the positive effects of globalization much more than others.

It is therefore important to give special attention to the case of Tunisia studying empirically the magnitude of the relationship between trade openness and inequality.

\section{Inequality in the Tunisian private sector}

In order to analyze the inequality of wage distribution in the Tunisian private sector, we conduct an econometric study through the EVIEWS software. Our study will focus on the effect of migration, labor force, and export of high technology, unemployment and human capital on inequality, so we propose the following model:

$\mathrm{TH}=\beta 1+\beta 2 \mathrm{HT}+\beta 3 \mathrm{UE}+\beta 4 \quad \mathrm{LF}+\beta 5 \mathrm{HK}+\beta 6 \mathrm{UR}$

With:

TH: Theil Index on the inequality of wage distribution by branch of economic activity.

$\mathrm{HT}$ : Annual growth rate of exports of high technology.

UE: Unemployment Rate.

LF: Annual growth rate of the labor force in the private sector.

HK: enrollment at tertiary level.

UR: Annual growth rate of the urban population.

In this context, in order to analyze and interpret the inequality between workers in the private sector, we consider several sectors of economic activity involving agriculture industry and service, and we calculate the inequality of wage distribution through the Theil index which defines as follows:

$$
\mathbf{T}_{(\mathbf{x}, \mathbf{n})}=\mathbf{1 / n} \sum_{i=1}^{n} \frac{X_{i}}{\bar{X}} \log \frac{X_{i}}{\bar{X}}
$$

We note that:

$\mathrm{X} \mathrm{i}=$ wage by sector of economic activity.

$\bar{X}=$ Average of all wages.

$\mathrm{N}=$ total number of sectors.

To ensure the stationarity of variables, we conducted the unit root tests. We verified that the variables are stationary at the $1 \%$ level. The estimation results based on data relating to the 
National Social Security Fund and World Development Indicators for a study period from 1980 to 2011 are as follows:

Table 1. Estimation Results

\begin{tabular}{|l|c|c|}
\hline Variables & Coefficient & t-statistic \\
\hline C & -7.733 & -2.781 \\
\hline HT & 0.364 & 2.092 \\
\hline UE & 0.136 & 2.512 \\
\hline LF & 0.618 & 2.442 \\
\hline HK & -0.167 & -2.563 \\
\hline UR & -0.726 & -2.097 \\
\hline R-squared & 0.894 & \\
\hline F-statistic & 42.284 & \\
\hline
\end{tabular}

It follows from this econometric study:

- The growth of the urban population decreases wage disparities between branch of economic activity, Indeed, the migration of a number of workers in the agricultural rural sector to the urban industrial sector can be beneficial for the first since these workers, mostly unskilled, will shrink inequalities within the rural sector. The departure of these workers does not affect agricultural productivity, those who remain, will enjoy and benefit from an increase in their income, which will tend to minimize inequalities between economic sectors. Except that migration beyond a certain threshold causes a widening of social disparity.

- The private sector of the Tunisian labor market depends on the availability of the labor force. Indeed, if labor is abundant, entrepreneurs tend to take advantage of this abundance by hiring with less pay and also with the minimum commitments from titularization of workers, Which disrupts the workers in this sector and led to an increase in inequality between workers already tenured and the others on the market. The unemployment rate has increased in recent years affecting inequality since the demand of employment is related to a definite category, it focuses in particular on those that are more adaptable to the continuing spread of technologies.

- The export of new technologies positively affects the inequality wage distribution, indeed, with the increased competition in the market; firms adopt strategies intensive skilled labor that reinforces wage inequalities between workers. The high sensitivity of inequality to the qualification is well recognized, in this regard, an effort should be particularly focused on vocational training policies in order to evolve unskilled workers so that they can best meet the requirements of new technologies.

\section{Conclusion}

The issue of inequality has become a theoretical tool to highlight the limits of effectiveness of structural adjustment programs published by international institutions and listed in poor countries. These are often forced to join political extraversion the price of a hope of catching up. 
Indeed, debates are not only economic, but also social and political crystallize around this notion of openness to the world economy, sometimes presented as a panacea for all problems of the world, sometimes as a threat to the sovereignty of peoples and nations.

By focusing on the structure of the labor market on the eve of globalization, we note that it is strongly marked by the segmentation and inequality among workers. In this regard, the econometric study showed the negative effect of openness on inequality that has steadily increased in the private sector. Inequality explained by the increase in unemployment and hiring managers with low wages. The rise in inequality between workers is a major cause of increased social inequalities within countries.

\section{References}

Banque Mondiale (91), World Development Report 1991: "The Challenge of Development", Oxford University Press, New York.

Banque Mondiale (1997), "L'Etat dans un monde en mutation", Rapport sur le Développement dans le Monde.

Hugon.F (99), "Le consensus de Washington en question", Revue Tiers Monde, XL, $\mathrm{n}^{\circ}$ 157, janvier - mars, PP : 10-36.

Milanovic. B (2003), "The Two Faces of Globalization: Againt Globalization as we know it", World Development (31), (4), PP: 967-683.

Rodrik.D (98), "Why Do More Open Economies have Bigger Government", Journal of political Economy (106), (5), PP: 997-1032.

Rodrik.D (2004), "Growth Strategies", Harvard University, October.

Rodrik.D (2006), "Goodbye Washington Consensus, Hello Washington Confusion", Harvard University, January.

Stiglitz.J.E (98), "More Instrument and Broader Goals: Moving to Ward the Past-Washington Consensus", WIDER Lecture, Helsinki.

Stiglitz.J.E (98), "Towards a New Parading for Development: Strategies, Policies and Processes", Prebish lecture, Geneva, 19 October.

Treval.A.M (2003), "L'Afrique et le consensus de Washington : trouver la bonne voie", Finance et Développement, septembre, PP : 18-20.

Williamson J. (1990), “Latin American Adjustment: How Much Has Happened?", Institute for International Economics, Washington.

Williamson.J (2004), "The Washington Consensus as Policy Prescription for Development", Practioners of Development Lecture, Washington, 13 January.

World Bank (91), World Development Report 1991, "The Challenge of Development", Oxford University Press, New York.

World Bank (1997), “L'Etat dans un monde en mutation”, Rapport sur le Développement dans le Monde. http://econ.worldbank.org 